\title{
Pyriform Sinus Fistula in the Fetus and Neonate: A Systematic Review of Published Cases
}

\author{
Tong Chen, Jianglong Chen, Qingfeng Sheng, Linlin Zhu and Zhibao Lv* \\ Department of General Surgery, Shanghai Children's Hospital, Shanghai Jiao Tong University, Shanghai, China
}

Purpose: To provide recommendations for the diagnosis and treatment of pyriform sinus fistula (PSF) in the fetus and neonate through a systematic review of the published literature.

Methods: PubMed and Embase (1968-2019) were searched, and additional publications were obtained by searching the references by hand. The two reviewers assessed all papers and extracted the following variables: demographics, clinical features, diagnostic tests, interventions, and prognoses.

Results: Forty-two papers were included, comprising a total of 158 cases. PSF presented almost exclusively on the left side (95.56\%). Patients usually presented with

OPEN ACCESS

Edited by:

Francesco Morini,

Bambino Gesù Children Hospital

(IRCCS), Italy

Reviewed by:

Paola Midrio,

Ca' Foncello Hospital, Italy

Hiromu Miyake,

Shizuoka Children's Hospital, Japan

*Correspondence:

Zhibao LV

zhibaolyu@sina.cn

Specialty section:

This article was submitted to

Pediatric Surgery,

a section of the journal

Frontiers in Pediatrics

Received: 23 April 2020

Accepted: 16 July 2020

Published: 25 August 2020

Citation:

Chen T, Chen J, Sheng Q, Zhu L and Lv Z (2020) Pyriform Sinus Fistula in the Fetus and Neonate: A Systematic

Review of Published Cases.

Front. Pediatr. 8:502

doi: 10.3389/fped.2020.00502 a neck mass (100\%) and respiratory distress (43.18\%). The false-negative rate (FNR) of prenatal ultrasonography (US) was significantly higher than that of prenatal magnetic resonance imaging (MRI) $(P<0.01)$. For the diagnosis of PSF in neonates, computerized tomography $(\mathrm{CT})$ and $\mathrm{MRI}$ were the most accurate diagnostic modalities. Ex utero intrapartum treatment (EXIT) was performed during delivery in 6 patients (26.09\%). Among 135 patients with a reported date of definitive surgery, 117 (86.67\%) underwent surgery during the neonatal period. Complications after definitive surgery appeared in 5 patients (3.16\%), and all of them recovered spontaneously within 3 months. Furthermore, recurrence occurred in 4 patients (2.53\%).

Conclusion: In fetal cases with PSF suspected by US, MRI is necessary to confirm the diagnosis. During the neonatal period, patients with PSF typically present with a neck mass and respiratory distress, and CT/MRI appears to be the preferred diagnostic method. Definitive surgery is effective for treating neonatal PSF, with a low complication rate and low recurrence rate.

Keywords: diagnosis, fetus, neonate, pyriform sinus fistula, treatment

\section{INTRODUCTION}

Pyriform sinus fistula (PSF), constituting $<2 \%$ of branchial cleft anomalies (1), is a congenital entity due to abnormal development of the third or fourth branchial cleft (2). Anatomically, PSF begins at the pyriform fossa, penetrates the cricothyroid muscle, and terminates laterally in the thyroid gland $(3,4)$.

Approximately $80 \%$ of patients with PSF show onset in the neonatal or pediatric period (5). Children with PSF often present with recurrent neck abscesses and acute thyroiditis. In contrast, 
neck masses and respiratory problems are the main presentations in neonates with PSF, and tracheal compression may lead to apnea. Therefore, the diagnosis of PSF in the fetus and neonate has been widely acknowledged as a growing concern (6-10). In addition to the clinical presentations, the preferred imaging test between children and neonates is also quite different (11). Although the first PSF case reported in the literature was a 3-week-old neonate (12), the majority of reported PSF cases are children. Collectively, the underreported condition of PSF in the fetus and neonate has given rise to frequently delayed diagnosis or misdiagnosis. Furthermore, there are few recommendations for the diagnosis and treatment of this entity, and the preferred method of definitive surgery is yet to be determined. Therefore, we performed a review of all published fetal and neonatal cases of PSF to summarize the clinical characteristics and to investigate the preferred options for diagnosis and treatment.

\section{MATERIALS AND METHODS}

\section{Registration and Search Strategy}

This systematic review was registered in the International Prospective Register of Systematic Reviews (PROSPERO) CRD42020160755. Cases were identified by detailed searches of PubMed and Embase with the following word combinations: ("piriform sinus tract" OR "piriform sinus fistula" OR "piriform sinus cyst" OR "third branchial cleft anomaly" OR "fourth branchial cleft anomaly") AND ("prenatal" OR "fetus" OR "in utero" OR "neonate" OR "newborn"). Included papers

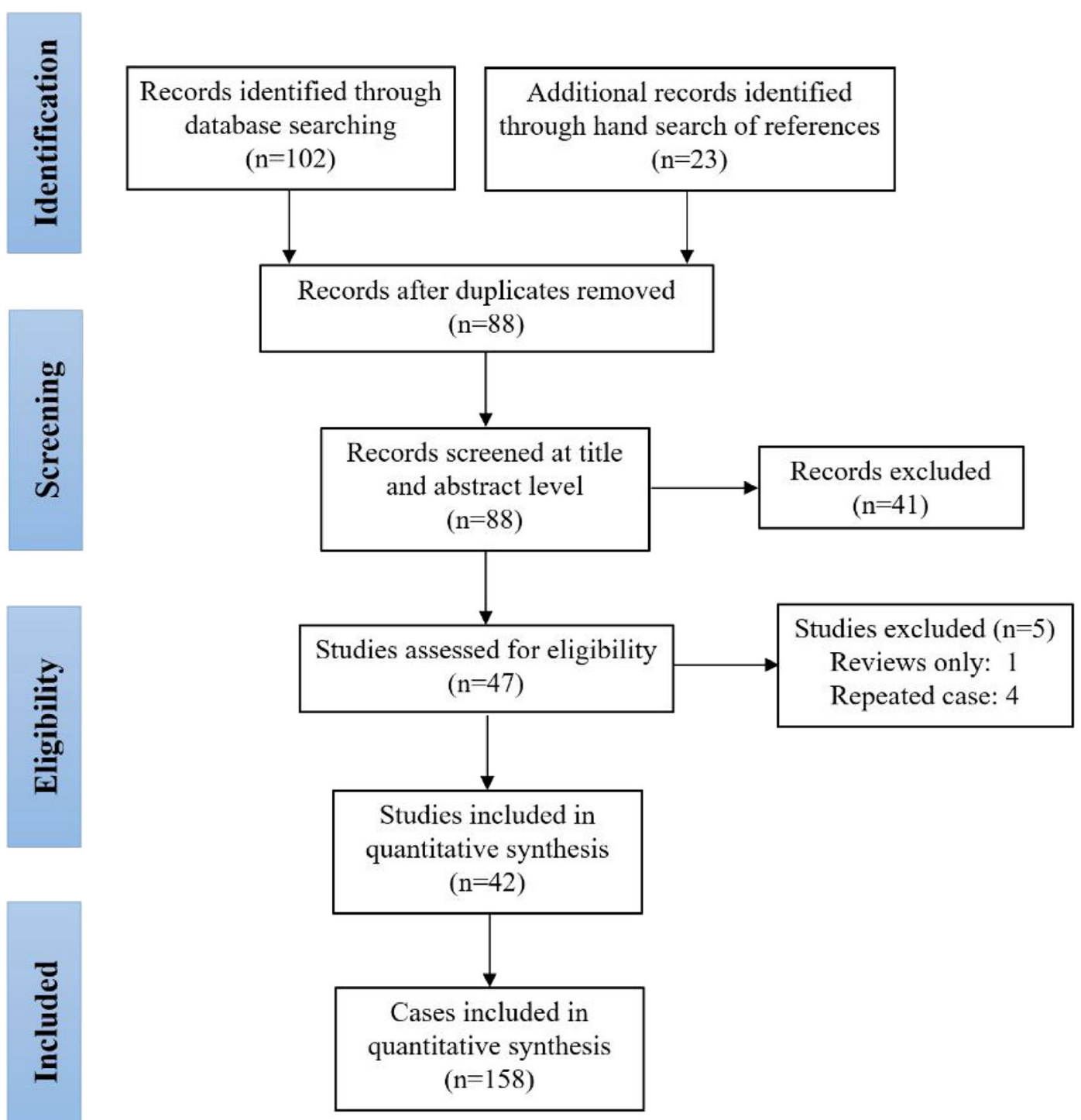

FIGURE 1 | Flowchart of the search strategy and included studies. 
were restricted to those published between 1968 and 2019 . Furthermore, we did not evaluate papers without Englishlanguage abstracts. The searching and screening of papers and abstracts were conducted independently by two reviewers (TC, JC), and the references of selected papers were also checked to identify other eligible studies. Inconsistent results found by the two reviewers were further assessed and discussed to reach a consensus. Figure 1 illustrates the detailed flowchart of the search strategy, and 42 studies were included in this review $(6,9-11,13-50)$.

\section{Inclusion Criteria}

We included patients who were diagnosed with PSF by imaging or endoscopic procedures during the prenatal or neonatal period and who had surgically confirmed PSF reported in the study. Thus, patients newly diagnosed with PSF by imaging or endoscopic procedures after the neonatal period were excluded.

\section{Diagnostic Criteria}

The diagnosis of PSF in the fetus was made when ultrasonography (US) or magnetic resonance imaging (MRI) showed a single-cystic mass in the neck, usually on the left side, located near the thyroid gland beneath the laryngeal fossa. The diagnosis of PSF in the neonate was made when at least one of the following criteria was met: (1) US, computerized tomography (CT) or MRI demonstrated a simple cystic mass in the neck, especially on the left side, usually with an air-fluid level in the cyst; (2) barium esophagography delineated the fistulous tract; or (3) the inner orifice of the fistulous tract was detected by endoscopic procedures.

\section{Data Extraction}

The two reviewers assessed all relevant papers and extracted the following variables: demographics, clinical features, diagnostic tests, treatments, postoperative pathological examination results, complications, and cases of recurrence.

\section{Statistical Analysis}

Statistical Package for the Social Sciences software (version 22.0, Chicago, USA) was applied for data analyses. Continuous variables were recorded as the mean and standard deviation, whereas categorical variables were described as $\mathrm{N}$ with percentage. The false-negative rate (FNR) was computed as the number of false-negative (FN) results/(the number of true-positive [TP] results + the number of FN results). The proportions of different groups were compared using $\chi^{2}$. A twosided confidence level of $P<0.05$ indicated significance.

\section{RESULTS}

\section{Demographics and Clinical Features}

One hundred and fifty-eight cases were enrolled in this review. The male-to-female ratio was $1.42: 1$, which yielded a male predominance. PSF occurred almost exclusively on the left side. Patients with PSF usually presented with various degrees of neck masses and respiratory distress (Table 1). In addition, neck infection and fever occurred in 36.36 and $11.36 \%$ of the neonates, respectively. The maximum size of the neck mass in the neonates ranged from 2.2 to $6.0 \mathrm{~cm}$ (mean: $4.71 \mathrm{~cm}$ ). The mean maternal age was $27.90 \pm 5.67$ years, ranging from 19 to 41 years. Eight patients (5.06\%) developed neck infections during the neonatal period.

TABLE 1 | Characteristics of the included neonates with PSF.

\begin{tabular}{|c|c|c|}
\hline Characteristics & $N$ & $\%$ \\
\hline \multicolumn{3}{|l|}{$\operatorname{Sex}(n=138)$} \\
\hline Female & 57 & 41.30 \\
\hline Male & 81 & 58.70 \\
\hline \multicolumn{3}{|c|}{ Age at symptom onset $(n=38)$} \\
\hline$\leq 7$ & 15 & 39.47 \\
\hline$>8, \leq 28$ & 23 & 60.53 \\
\hline \multicolumn{3}{|l|}{ Side $(n=135)$} \\
\hline Left & 129 & 95.56 \\
\hline Right & 5 & 3.70 \\
\hline Bilateral & 1 & 0.74 \\
\hline \multicolumn{3}{|l|}{ Delivery mode $(n=51)$} \\
\hline Eutocia & 24 & 47.06 \\
\hline Cesarean & 27 & 52.94 \\
\hline \multicolumn{3}{|c|}{ Gestational weeks $(n=58)$} \\
\hline$\leq 36$ & 4 & 6.90 \\
\hline$>37, \leq 40$ & 45 & 77.59 \\
\hline$>40$ & 9 & 15.52 \\
\hline \multicolumn{3}{|l|}{ Birth weight $(n=41)$} \\
\hline Low birth weight & 3 & 7.32 \\
\hline Normal birth weight & 38 & 92.68 \\
\hline \multicolumn{3}{|l|}{ Presentation $(n=132)$} \\
\hline Neck mass & 132 & 100 \\
\hline Respiratory distress & 57 & 43.18 \\
\hline Infection & 8 & 6.06 \\
\hline Fever & 15 & 11.36 \\
\hline
\end{tabular}

PSF, pyriform sinus fistula.

TABLE 2 | Results of different diagnostic tests of the included cases.

\begin{tabular}{lccc}
\hline Diagnostic test & Total cases & FN result & FNR (\%) \\
\hline $\begin{array}{l}\text { Prenatal imaging test } \\
\quad \text { US }\end{array}$ & 54 & 39 & 72.22 \\
$\quad$ MRI & 13 & 3 & 23.08 \\
Neonatal test & & & \\
US & 19 & 9 & 47.37 \\
CT & 98 & 25 & 25.51 \\
MRI & 27 & 6 & 22.22 \\
Barium esophagography & 93 & 48 & 51.61 \\
$\quad$ Laryngoscopy or esophagoscopy & 33 & 11 & 33.33 \\
\hline
\end{tabular}

$C T$, computed tomography; FN, false-negative, FNR, false-negative rate; MRI, magnetic resonance imaging; PSF, pyriform sinus fistula; US, ultrasonography. 


\section{Diagnostic Test}

The FN result and FNR of each diagnostic test performed prenatally or postnatally are listed in Table 2. The earliest detection of a neck mass using prenatal US was during the 18th week of gestation. Overall, twenty-three patients (14.56\%) were prenatally diagnosed with PSF using US and/or MRI. Prenatal US yielded a significantly higher FNR than prenatal MRI $(P<$ 0.01 ). Furthermore, the FNR of CT or MRI performed after birth was significantly lower than that of US, barium esophagography, laryngoscopy and esophagoscopy $(P<0.05)$.

\section{Treatments and Outcomes}

Ex utero intrapartum treatment (EXIT) was performed during delivery in 6 patients $(26.09 \%)$. Preoperative incubation was conducted in 14 patients $(8.86 \%)$. Twenty-five patients (15.82\%) underwent incision and drainage. Among 135 patients with a reported date of definitive surgery, 117 patients (86.67\%) underwent definitive surgery during the neonatal period, whereas 18 patients $(13.33 \%)$ underwent definitive surgery after the neonatal period. The specific type of definitive surgery was reported in 126 cases. Endoscopic-assisted surgery was performed in 60 cases $(47.62 \%)$, and traditional open neck surgery was performed in 52 cases (41.27\%). In addition, fourteen patients $(11.11 \%)$ underwent cauterization of the inner orifice. The results of histopathologic examinations were described in 100 cases (63.29\%); among them, squamous epithelium, respiratory epithelium, and inflammatory cells constituted the majority of conditions. Additionally, thyroid, thymic, and parathyroid tissues were sometimes demonstrated. The followup duration ranged from 6 to 180 months (mean: 47.52 months). Complications appeared in 5 patients (Table 3), and all of them recovered spontaneously within 3 months after surgery.

TABLE 3 | Complications of definitive surgeries for neonatal PSF in 5 cases.

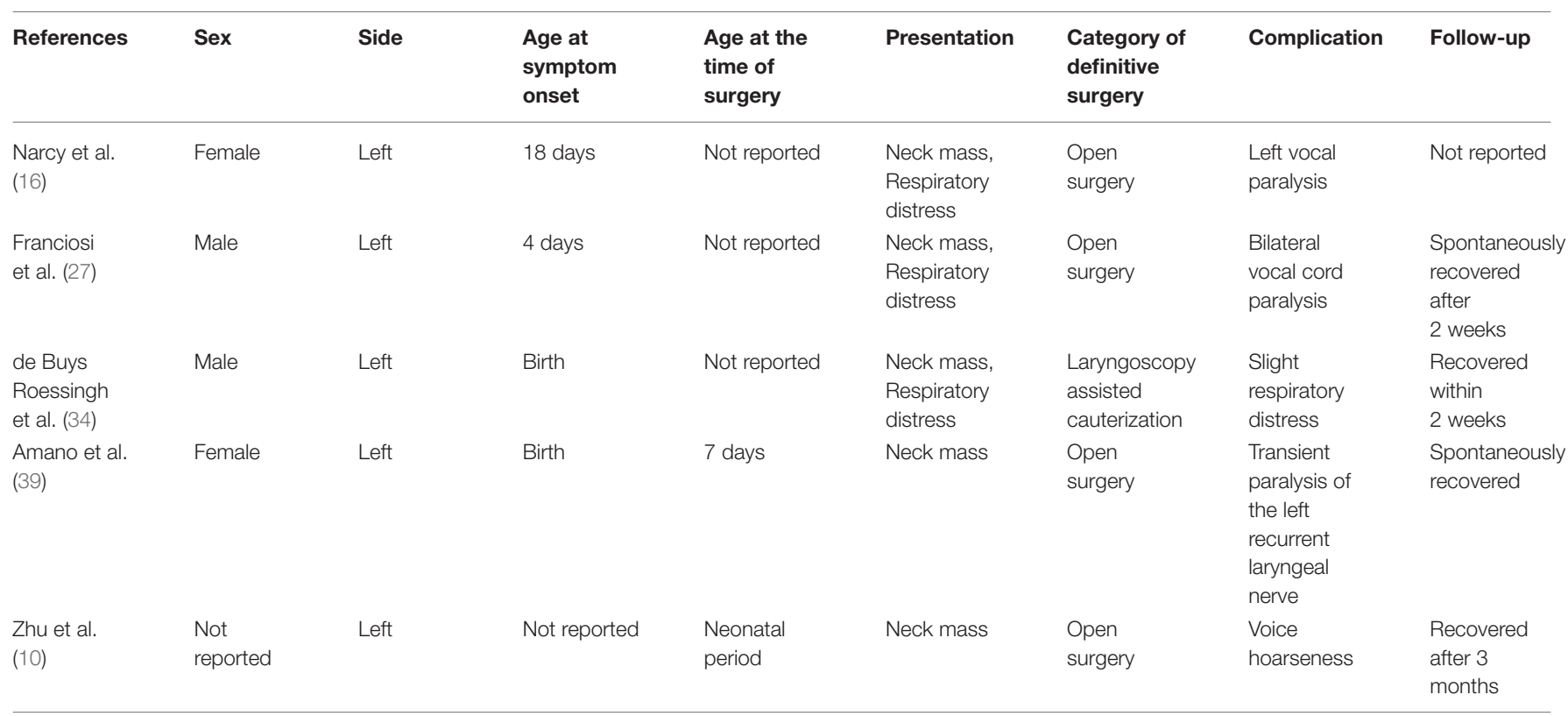

TABLE 4 | Reported recurrences after definitive surgeries for neonatal PSF in 4 cases.

\begin{tabular}{|c|c|c|c|c|c|c|c|c|c|}
\hline References & Sex & Side & $\begin{array}{l}\text { Age at } \\
\text { symptom } \\
\text { onset }\end{array}$ & $\begin{array}{l}\text { Age at the } \\
\text { time of } \\
\text { surgery }\end{array}$ & Presentation & $\begin{array}{l}\text { First } \\
\text { definitive } \\
\text { surgery }\end{array}$ & Recurrence & $\begin{array}{l}\text { Final } \\
\text { surgery }\end{array}$ & $\begin{array}{l}\text { Age at the } \\
\text { time of final } \\
\text { surgery }\end{array}$ \\
\hline $\begin{array}{l}\text { Leboulanger } \\
\text { et al. (38) }\end{array}$ & $\begin{array}{l}\text { Not } \\
\text { reported }\end{array}$ & $\begin{array}{l}\text { Not } \\
\text { reported }\end{array}$ & Not reported & Not reported & Neck mass & $\begin{array}{l}\mathrm{CO}_{2} \text { laser } \\
\text { cauterization }\end{array}$ & Neck mass & $\begin{array}{l}\text { Open } \\
\text { surgery }\end{array}$ & $\begin{array}{l}3 \text { days after } \\
\text { the first } \\
\text { surgery }\end{array}$ \\
\hline $\begin{array}{l}\text { Hwang et al. } \\
\text { (45) }\end{array}$ & $\begin{array}{l}\text { Not } \\
\text { reported }\end{array}$ & $\begin{array}{l}\text { Not } \\
\text { reported }\end{array}$ & Not reported & Not reported & Neck mass & $\begin{array}{l}\text { Open } \\
\text { surgery }\end{array}$ & $\begin{array}{l}\text { Neck } \\
\text { inflammation }\end{array}$ & $\begin{array}{l}\text { Open } \\
\text { surgery }\end{array}$ & Not reported \\
\hline
\end{tabular}




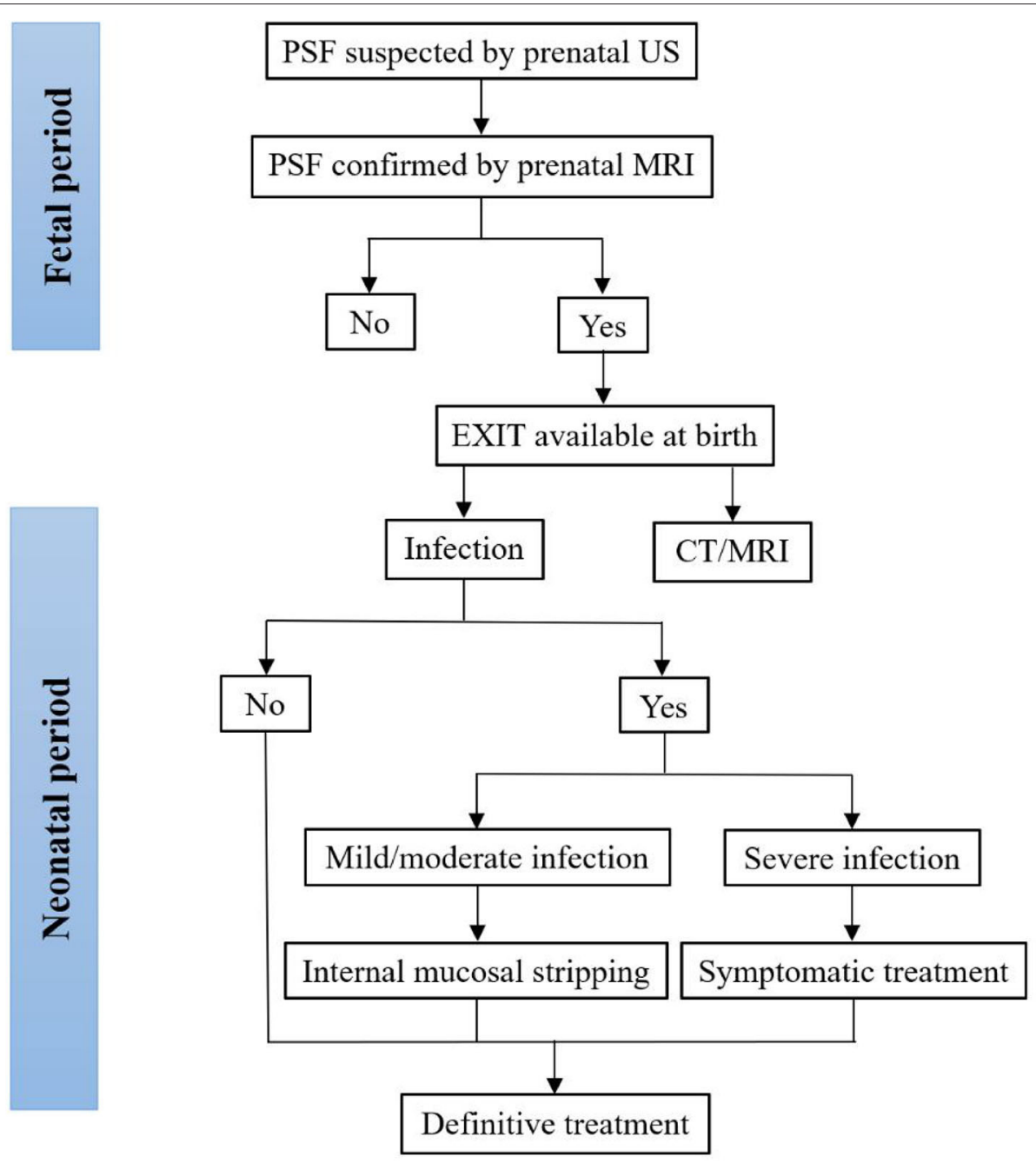

FIGURE 2 | Tentative algorithm for the diagnosis and treatment of PSF in the fetus and neonate. CT, computed tomography; MRI, magnetic resonance imaging; PSF, pyriform sinus fistula; US, ultrasonography.

Furthermore, recurrence occurred in 4 patients (Table 4). Specifically, recurrence appeared in 2 patients after open neck surgery, and the other 2 patients experienced recurrence after cauterization.

\section{DISCUSSION}

PSF is characterized by incomplete obliteration of the third or fourth pharyngeal pouch linked with the pyriform sinus, which ought to involute during the 7 th week of gestation (12). Although severe neck infection was reported to be fatal in an adult with PSF (51), PSF usually gives rise to non-lethal outcomes in children, which reveals the benign nature of the disease. However, respiratory distress, one common presentation in neonates with PSF, has the potential to cause life-threatening complications. Delayed diagnosis or misdiagnosis of neonatal PSF is quite common due to its rarity. Therefore, it is essential to provide recommendations regarding diagnosis and treatment of neonatal PSF.

In this review, $95.56 \%$ of PSF cases presented on the left side. This left-sided predominance could be attributable to the degeneration of the right ultimobranchial body, the more complicated fistulous tract on the left side (52), and asymmetric vascular agenesis (3). As PSF is located close to the respiratory tract and may lead to high pressure in the trachea, EXIT is sometimes necessary during delivery (53). The main presentations of neonates with PSF are neck mass and respiratory distress. In contrast, PSF often presents as recurrent cervical inflammation and acute suppurative thyroiditis in children (39). One hypothesis is that the sinus tract alters the position along with aging. Specifically, the tract is situated near the pyriform sinus in the neonate, and moves lower in the neck after the neonatal period. The other hypothesis is that the cartilage of neonatal the trachea is weak and less robust during the neonatal period. The adverse impact of neonatal PSF is dependent on its 
size and location and on the presence of neck infections (34). After oral feeding, the size of the neck mass gradually increases in some cases $(32,44)$, which may lead to tracheal compression.

The accurate diagnosis of PSF in the fetus is important, because it can help clinicians preplan the timing of postnatal treatment. However, the diagnosis of fetal PSF remains a great challenge for radiologists due to the small cyst size. This review revealed 23 cases with a prenatal diagnosis of PSF $(6,7,9$, $24,32,54)$. PSF-related neck abnormality is often identified in the second or third trimester. To date, the earliest detection of PSF-related abnormality was achieved during the 18th week of gestation using prenatal US (4). Our data demonstrated that the FNR of fetal MRI was significantly lower than that of fetal US. For the differential diagnosis of PSF, lymphangioma, thyroid cysts, cystic hygroma, and esophageal cysts should be taken into consideration. Specifically, lymphangioma is often combined with other malformations, which together lead to fetal hydrops. In addition, lymphangioma is usually detected in early gestation and in the posterior cervical space (55). Thyroid cyst is characterized by round cyst in the parenchyma of the thyroid, and the wall of thyroid cyst is thinner than that of PSF. With the help of US and MRI, the accurate diagnosis of fetal PSF is possible $(8,56)$.

Multiple diagnostic methods, including laryngoscopy, barium esophagography, US, CT, and MRI, have been adopted for the diagnosis of neonatal PSF (52, 57-61). US is often regarded as the initial screening test. In this review, the FNR of barium esophagography was $51.61 \%$, which was the most insensitive test for diagnosing neonatal PSF. The narrow orifice of the fistulous tract might prevent barium from penetrating, contributing to the FN results (62). Thus, it is inadvisable to perform barium esophagography for the evaluation of neonatal PSF. Both CT and MRI are considered reliable diagnostic methods to evaluate neonatal PSF (11). Compared with MRI, CT is much cheaper and more readily and widely available but yields additional radiation exposure. The diagnosis of PSF can be made when CT shows an air-fluid level in the cyst. In addition, the anatomical association between the tract and the thyroid can also be assessed using CT (63). On the other hand, MRI may distinguish the inflammatory condition of the tract but cannot detect air in the cyst (64).

Treatment options for neonatal PSF depend on whether there are neck infections. Recently, it was reported that neck infections were uncommon in neonates with PSF, particularly during the period from 0 to 7 days after birth $(10,11)$, and the optimal timing for definitive surgery was 0-7 days after birth (10), yielding no complications or cases of recurrence $(8,46)$. Similarly, the majority of neonates with PSF in this review did not develop neck infections. Various definitive surgeries were

\section{REFERENCES}

1. Goins MR, Beasley MS. Pediatric neck masses. Oral Maxil Surg Clin. (2012) 24:457-68. doi: 10.1016/j.coms.2012.05.006

2. Chaudhary N, Gupta A, Motwani G, Kumar S. Fistula of the fourth branchial pouch. Am J Otolaryngol. (2003) 24:2502. doi: 10.1016/S0196-0709(03)00026-7 demonstrated in the included papers. Traditional open neck surgery and endoscopic-assisted surgery were the two mainstay treatments for neonatal PSF. A minority of patients underwent cauterization using $\mathrm{CO}_{2}$ or a thulium laser. Cauterization of the internal orifice offered no skin incision requirement, easier identification of the tract and a shorter hospitalization time, and it has become popular for the treatment of PSF in children. However, it is difficult to perform endoscopic procedures in neonates, such as the placement of an endoscope inside the narrow oropharyngeal space. The tentative algorithm for the diagnosis and treatment of PSF in the fetus and neonate is plotted in Figure 2. Before the first episode of inflammation, one-stage definitive surgery can be performed. In neonates with mild or moderate infections, since inflammatory adhesions surround the tract, internal mucosal stripping should be performed to avoid postoperative complications. Fluctuations in neck swelling and skin redness suggest severe neck infection. Under this condition, incision, and drainage with broad-spectrum antibiotics should be adopted. Inflammation subsides after at least 4 weeks. Then, definitive surgery can be performed $(61,62,65)$.

The current study has some limitations. First, the included cases were extracted from a large and heterogeneous collection of case reports and small case series, varying in terms of methodology and description of clinical features. Therefore, detailed statistical analyses conducted in a meta-analysis of studies are not suitable for this review. In addition, the review may be limited by potential publication bias. Finally, our recommendations were based on a small population size and should be verified by further studies with larger sample sizes, in particular, randomized control trials.

In conclusion, in fetal cases of PSF suspected by US, it is advisable to perform MRI to further confirm the diagnosis. During the neonatal period, PSF patients typically present with neck mass and respiratory distress. Both CT and MRI appear to be the preferred modalities for the diagnosis of neonatal PSF. Definitive surgery is effective for treating neonatal PSF, with a low complication rate and low recurrence rate.

\section{DATA AVAILABILITY STATEMENT}

All datasets generated for this study are included in the article/supplementary material.

\section{AUTHOR CONTRIBUTIONS}

TC and ZL: study design. TC, JC, and QS: collection and analysis of data. TC, JC, and LZ: manuscript writing. All authors: contributed to the article and approved the submitted version. 
5. Miyauchi A, Matsuzuka F, Takai SI, Kuma K, Kosaki G. Piriform sinus fistula: a route of infection in acute suppurative thyroiditis. Arch Surg. (1981) 116:66-9. doi: 10.1001/archsurg.1981.01380130044010

6. Kakogawa J, Nako T, Igarashi S, Nakamura S, Tanaka M. Prenatal diagnosis of pyriform sinus fistula: case report and literature review. Clin Case Rep. (2015) 3:106-9. doi: $10.1002 / \mathrm{ccr} 3.166$

7. Zeng SH, Liu HS, Zhong W, Liu ZQ, He QM, Han J, et al. Can we make an accurate diagnosis of pyriform sinus fistula by fetal MRI? Clin Radiol. (2016) 71:837-43. doi: 10.1016/j.crad.2016.05.012

8. Zhong W, Wang Z, He QM, Shi TT, Yu JK, Zhang GL, et al. Prenatal diagnosis and early postnatal management of pyriform sinus cyst: experience at a single medical center in mainland China. Prenatal Diag. (2016) 36:1041. doi: 10.1002/pd.4930

9. Liu Z, Han J, Fu F, Liu HS, He QM, Zhong W, et al. How to make an accurate diagnosis of fetal pyriform sinus fistula in utero: experience at a single medical center in mainland China. Eur J Obstet Gyn R B. (2018) 228:76-81. doi: 10.1016/j.ejogrb.2018.05.039

10. Zhu H, Xiao X, Zheng S, Shen C. Diagnosis and management of pyriform sinus cyst in neonates: 16-year experience at a single center. J Pediatr Surg. (2017) 52:1989-93. doi: 10.1016/j.jpedsurg.2017.08.041

11. Pan J, Zou Y, Li L, Yang TY, Yang JL, Hu C. Clinical and imaging differences between neonates and children with pyriform sinus fistula: which is preferred for diagnosis, computed tomography, or barium esophagography? J Pediatr Surg. (2017) 52:1878-81. doi: 10.1016/j.jpedsurg.2017.08.006

12. Raven RW. Pouches of the pharynx and œoesophagus with special reference to the embryological and morphological aspects. Brit J Surg. (1933) 21:23556. doi: 10.1002/bjs.1800218208

13. Andrieu-Guitrancourt J, Narcy P, Borde J, Melin Y, Manac'h Y, Dehesdin D, et al. Digestive duplications affecting the pharynx or fistulae of the fourth endo-branchial pouch. four cases (author's transl). Annales D Otolaryngologie Et De Chirurgie Cervico Faciale. (1980) 96:863-79.

14. Burge D, Middleton A. Persistent pharyngeal pouch derivatives in the neonate. J Pediatr Surg. (1983) 18:230-4. doi: 10.1016/S0022-3468(83)80090-6

15. Miller D, Hill JL, Sun CC, O'Brien DS, Haller JA. The diagnosis and management of pyriform sinus fistulae in infants and young children. JPediatr Surg. (1983) 18:377-81. doi: 10.1016/S0022-3468(83)80185-7

16. Narcy P, Aumont-Grosskopf C, Bobin S, Manac' HY. Fistulae of the fourth endobranchial fistula. Int J Pediatr Otorhi. (1988) 16:157-65. doi: 10.1016/S0165-5876(98)90040-4

17. Tyler D, Effmann E, Shorter N. Pyriform sinus cyst and fistula in the newborn: the value of endoscopic cannulation. J Pediatr Surg. (1992) 27:15001. doi: 10.1016/0022-3468(92)90483-N

18. Vade A, Griffiths A, Hotaling A, Eisenbeis JF, Husain AN. Thymopharyngeal duct cyst: MR imaging of a third branchial arch anomaly in a neonate. J Magn Reson Imaging. (1994) 4:614-6. doi: 10.1002/jmri.1880040417

19. Sharma HS, Razif A, Hamzah M, Dharap AS, Mahbar Z, Kamal MZM, et al. Fourth branchial pouch cyst: an unusual cause of neonatal stridor. Int J Pediatr Otorhinolaryngol. (1996) 38:155-61. doi: 10.1016/S0165-5876(96)01424-3

20. Mahomed A, Youngson G. Congenital lateral cervical cysts of infancy. J Pediatr Surg. (1998) 33:1413-5. doi: 10.1016/S0022-3468(98)90022-7

21. Mizuno R, Yamazaki Y, Yoshida T, Kurobe M. Pyriform sinus fistula appearing as a neck tumor in the neonatal period: a case report. Pediatr Surg Int. (1998) 14:82-3. doi: 10.1007/s003830050442

22. Mouri N, Muraji T, Nishijima E, Tsugawa C. Reappraisal of lateral cervical cysts in neonates: pyriform sinus cysts as an anatomy-based nomenclature. J Pediatr Surg. (1998) 33:1141-4. doi: 10.1016/S0022-3468(98)90547-4

23. Yang C, Cohen J, Everts E, Smith J, Caro J, Andersen P. Fourth branchial arch sinus: clinical presentation, diagnostic workup, and surgical treatment. Laryngoscope. (1999) 109:442-6. doi: 10.1097/00005537-199903000-00019

24. Chin AC, Radhakrishnan J, Slatton D, Geissler G. Congenital cysts of the third and fourth pharyngeal pouches or pyriform sinus cysts. J Pediatr Surg. (2000) 35:1252-5. doi: 10.1053/jpsu.2000.8766

25. Robichaud J, Papsin BC, Forte V. Third branchial cleft anomaly detected in utero. J Otolaryngol-Head N. (2000) 29:185-7.

26. Hwang TZ, Lin YJ, Tsai ST. Fourth branchial cyst presenting with neonatal respiratory distress. Ann Otol Rhinol Laryngol. (2000) 109:4314. doi: $10.1177 / 000348940010900415$
27. Franciosi JP, Sell LL, Conley SF, Bolender DL. Pyriform sinus malformations: a cadaveric representation. J Pediatr Surg. (2002) 37:533-8. doi: 10.1053/jpsu.2002.30866

28. Liberman M, Kay S, Emil S, Flageole H, Nguyen LT, Tewfik TL, et al. Ten years of experience with third and fourth branchial remnants. J Pediatr Surg. (2002) 37:685-90. doi: 10.1053/jpsu.2002.32253

29. Garel L, Lucaya J, Piqueras J. Pyriform sinus fistula causing a neck abscess. Pediatr Radiol. (2003) 33:819-20. doi: 10.1007/s00247-0030990-x

30. Shrime M, Kacker A, Bent J, Ward RF. Fourth branchial complex anomalies: a case series. Int J Pediatr Otorhinolaryngol. (2003) 67:122733. doi: 10.1016/j.ijporl.2003.07.015

31. Pereira KD, Losh GG, Oliver D, Poole MD. Management of anomalies of the third and fourth branchial pouches. Int J Pediatr Otorhinolaryngol. (2004) 68:43-50. doi: 10.1016/j.ijporl.2003.09.004

32. Yanai T, Yamataka A, Kobayashi H, Lane GJ, Miyano T. Suspicion of prenatal pyriform sinus cyst and fistula: a case report. Pediatric Surg Int. (2004) 20:58. doi: 10.1007/s00383-003-1083-5

33. Horowitz E, Rabinerson D, Mashiach R, Shalev J, Meizner I. Ultrasound diagnosis of fourth branchial arch sinus at 22 weeks' gestation. Ultrasound Obstet Gynecol. (2006) 27:320-2. doi: 10.1002/uog.2643

34. de Buys Roessingh AS, Quintal MC, Dubois J, Bensoussan AL. Obstructive neonatal respiratory distress: infected pyriform sinus cyst. J Pediatr Surg. (2008) 43:E5-8. doi: 10.1016/j.jpedsurg.2007.12.071

35. Luers JC, Hoffmann B, Koerber F, Rahimi G, Streppel M. Piriform sinus fistula resulting in acute dyspnea in a newborn. HNO. (2008) 56:97580. doi: 10.1007/s00106-008-1696-Z

36. Joshi MJ, Provenzano MJ, Smith RJ, Sato Y, Smoker WR. The rare third branchial cleft cyst. AJNR Am J Neuroradiol. (2009) 30:18046. doi: 10.3174/ajnr.A1627

37. Lind R, Hulscher J, van der Wal J, Dikkers F, de Langen Z. A very rare case of a giant third branchial pouch remnant discovered in utero. Eur J Pediatr Surg. (2010) 20:349-51. doi: 10.1055/s-0029-1246194

38. Leboulanger N, Ruellan K, Nevoux J, Pezzettigotta S, Denoyelle F, Roger $\mathrm{G}$, et al. Neonatal vs delayed-onset fourth branchial pouch anomalies: therapeutic implications. Arch Otolaryngol Head Neck Surg. (2010) 136:88590. doi: 10.1001/archoto.2010.148

39. Amano H, Uchida H, Sato K, Kawashima H, Tanaka Y, Takazawa S, et al. Differences in the characteristics and management of pyriform sinus fistula between neonates and young children. Pediatr Surg Int. (2012) 28:1520. doi: 10.1007/s00383-011-3008-Z

40. Nathan K, Bajaj Y, Jephson CG. Stridor as a presentation of fourth branchial pouch sinus. J Laryngol Otol. (2012) 126:4324. doi: 10.1017/S0022215112000084

41. Patron V, Roudaut PY, Brosset P, Vivent M, Aubry K, Leboulanger N. Right fourth branchial cyst presenting as retropharyngeal collection in a neonate. J Perinatol. (2012) 32:153-5. doi: 10.1038/jp.2011.107

42. Kanazawa Y, Asai M, Adachi Y, Yoshida T, Itazawa T, Shimao A, et al. Retropharyngeal abscess in a neonate: a case report and literature review. Int $J$ Pediatr Otorhinolaryngol Extr. (2012) 7:115-8. doi: 10.1016/j.pedex.2012.03.003

43. Yoo TK, Kim SH, Kim HS, Kim HY, Park KW. Fourth branchial anomaly presenting with a lateral neck mass in a neonate. J Neo Surg. (2014) 3:34.

44. Patel JB, Kilbride H, Paulson L. Neonatal presentation of an air-filled neck mass that enlarges with Valsalva: a case report. AJP Rep. (2015) 5:e20711. doi: $10.1055 / \mathrm{s}-0035-1563388$

45. Hwang J, Kim SC, Kim DY, Namgoong JM, Nam SY, Roh JL. Excision vs. trichloroacetic acid (TCA) chemocauterization for branchial sinus of the pyriform fossa. J Pediatr Surg. (2015) 50:1949-53. doi: 10.1016/j.jpedsurg.2015.07.006

46. Hosokawa T, Yamada Y, Sato Y, Tanami Y, Amano H, Fujiogi M, et al. Five neonatal cases of pyriform sinus fistula with cervical cystic lesion: a comparison between sonography and other modalities. J Med Ultrason. (2015) 42:579-85. doi: 10.1007/s10396-015-0641-5

47. Chung MH, Kim SY, Lim GY, Chung JH. Two cases of pyriform sinus cyst in neonates: importance of early recognition and differential diagnosis. $A d v$ Pediatr Surg. (2018) 24:100-6. doi: 10.13029/aps.2018.24.2.100 
48. Hamaguchi N, Ishinaga H, Chiyonobu K, Morishita H, Takeuchi K. A case of pyriform sinus fistula with respiratory distress in the neonatal period. Case Rep Otolaryngol. (2018) 2018:1696875. doi: 10.1155/2018/1696875

49. Hosokawa T, Yamada Y, Takahashi H, Tanami Y, Sato Y, Hosokawa $\mathrm{M}$, et al. Optimal timing of the first barium swallow examination for diagnosis of pyriform sinus fistula. Am J Roentgenol. (2018) 211:11227. doi: 10.2214/AJR.18.19841

50. Rossi ME, Moreddu E, Leboulanger N, Akkari M, Triglia JM, Mondain M, et al. Fourth branchial anomalies: predictive factors of therapeutic success. J Pediatr Surg. (2019) 54:1702-7. doi: 10.1016/j.jpedsurg.2019.02.005

51. Tong F, Liang Y, Khan MF, Zhang L, Li W, Mahmoodurrahman M, et al. A fatal case of severe neck abscess due to a third branchial cleft fistula: morphologic and immunohistochemical analyses. Diagn Pathol. (2016) 11:87. doi: 10.1186/s13000-016-0540-0

52. Xiao X, Zheng S, Zheng J, Zhu L, Dong K, Shen C, et al. Endoscopicassisted surgery for pyriform sinus fistula in children: experience of 165 cases from a single institution. J Pediatr Surg. (2014) 49:61821. doi: 10.1016/j.jpedsurg.2013.11.004

53. Ayres AW, Pugh SK. Ex utero intrapartum treatment for fetal oropharyngeal cyst. Obstet Gynecol Int. (2010) 2010:273410. doi: 10.1155/2010/273410

54. Tsai PY, Chang CH, Chang FM. Prenatal imaging of the fetal branchial cleft cyst by three-dimensional ultrasound. Prenat Diagn. (2010) 23:6056. doi: 10.1002/pd.639

55. Gaddikeri S, Vattoth S, Gaddikeri RS, Stuart R, Harrison K, Young D, et al. Congenital cystic neck masses: embryology and imaging appearances, with clinicopathological correlation. Curr Probl Diagn Radiol. (2014) 43:5567. doi: 10.1067/j.cpradiol.2013.12.001

56. Mirsky DM, Shekdar KV, Bilaniuk LT. Fetal MRI: head and neck. Magn Reson Imaging Clin N Am. (2012) 20:605-18. doi: 10.1016/j.mric.2012.06.002

57. Wang HK, Tiu CM, Chou YH, Chang CY. Imaging studies of pyriform sinus fistula. Pediatr Radiol. (2003) 33:328-33. doi: 10.1007/s00247-003-0887-8

58. Ahuja AT, Griffiths JF, Roebuck DJ, Loftus WK, Lau KY, Yeung CK, et al. The role of ultrasound and oesophagography in the management of acute suppurative thyroiditis in children associated with congenital pyriform fossa sinus. Clin Radiol. (1998) 53:209-11. doi: 10.1016/S0009-9260(98)80102-5

59. Ahn D, Sohn JH, Kim H, Yeo CK. Clinical and microbiological differences between pyriform sinus fistulae in pediatric and non-pediatric patients. Auris Nasus Larynx. (2015) 42:34-8. doi: 10.1016/j.anl.2014.06.003

60. Sheng Q, Lv Z, Xiao X, Zheng S, Huang Y, Huang X, et al. Diagnosis and management of pyriform sinus fistula: experience in 48 cases. J Pediatr Surg. (2014) 49:455-9. doi: 10.1016/j.jpedsurg.2013.07.008

61. Sheng Q, Lv Z, Xiao X, Xu W, Liu J, Wu Y. Endoscopic-assisted surgery for pyriform sinus fistula in chinese children: a 73-consecutive-case study. J Laparoendosc Adv Surg Tech A. (2016) 26:70-4. doi: 10.1089/lap.2015.0129

62. Seki N, Himi T. Retrospective review of 13 cases of pyriform sinus fistula. Am J Otolaryngol. (2007) 28:55-8. doi: 10.1016/j.amjoto.2006.05.002

63. Masuoka H, Miyauchi A, Tomoda C, Inoue H, Takamura Y, Ito Y, et al. Imaging studies in sixty patients with acute suppurative thyroiditis. Thyroid. (2011) 21:1075-80. doi: 10.1089/thy.2010.0366

64. Thomas B, Shroff M, Forte V, Blaser S, James A. Revisiting imaging features and the embryologic basis of third and fourth branchial anomalies. Am J Neuroradiol. (2010) 31:755-60. doi: 10.3174/ajnr.A1902

65. Skuza K, Rapaport R, Fieldman R, Goldstein S, Marquis J. Recurrent acute suppurative thyroiditis. J Otolaryngol. (1991) 20:126-9.

Conflict of Interest: The authors declare that the research was conducted in the absence of any commercial or financial relationships that could be construed as a potential conflict of interest.

Copyright (C) 2020 Chen, Chen, Sheng, Zhu and Lv. This is an open-access article distributed under the terms of the Creative Commons Attribution License (CC BY). The use, distribution or reproduction in other forums is permitted, provided the original author(s) and the copyright owner(s) are credited and that the original publication in this journal is cited, in accordance with accepted academic practice. No use, distribution or reproduction is permitted which does not comply with these terms. 